\title{
A survey of immunohistochemical biomarkers for basal-like breast cancer against a gene expression profile gold standard
}

\author{
Jennifer R Won ${ }^{1,2}$, Dongxia Gao ${ }^{2}$, Christine Chow ${ }^{2}$, Jinjin Cheng ${ }^{2}$, Sherman YH Lau ${ }^{2}$, \\ Matthew J Ellis ${ }^{3}$, Charles M Perou ${ }^{4}$, Philip S Bernard ${ }^{5}$ and Torsten O Nielsen ${ }^{1,2}$ \\ ${ }^{1}$ Department of Pathology and Laboratory Medicine, University of British Columbia, Vancouver, British \\ Columbia, Canada; ${ }^{2}$ Genetic Pathology Evaluation Centre, University of British Columbia, Vancouver, \\ British Columbia, Canada; ${ }^{3}$ Division of Oncology, Department of Internal Medicine, Washington University, \\ St Louis, MO, USA; ${ }^{4}$ Department of Genetics, Lineberger Comprehensive Cancer Center, University of North \\ Carolina, Chapel Hill, NC, USA and ${ }^{5}$ Department of Pathology, University of Utah Health Sciences Center, \\ Salt Lake City, UT, USA
}

\begin{abstract}
Gene expression profiling of breast cancer delineates a particularly aggressive subtype referred to as 'basallike', which comprises $\sim 15 \%$ of all breast cancers, afflicts younger women and is refractory to endocrine and anti-HER2 therapies. Immunohistochemical surrogate definitions for basal-like breast cancer, such as the clinical ER/PR/HER2 triple-negative phenotype and models incorporating positive expression for CK5 (CK5/6) and/or EGFR are heavily cited. However, many additional biomarkers for basal-like breast cancer have been described in the literature. A parallel comparison of $\mathbf{4 6}$ proposed immunohistochemical biomarkers of basal-like breast cancer was performed against a gene expression profile gold standard on a tissue microarray containing 42 basal-like and 80 non-basal-like breast cancer cases. Ki67 and PPH3 were the most sensitive biomarkers (both 92\%) positively expressed in the basal-like subtype, whereas CK14, IMP3 and NGFR were the most specific (100\%). Among biomarkers surveyed, loss of INPP4B (a negative regulator of phosphatidylinositol signaling) was $61 \%$ sensitive and $99 \%$ specific with the highest odds ratio (OR) at 108, indicating the strongest association with basal-like breast cancer. Expression of nestin, a common marker of neural progenitor cells that is also associated with the triple-negative/basal-like phenotype and poor breast cancer prognosis, possessed the second highest OR at 29 among the 46 biomarkers surveyed, as well as $54 \%$ sensitivity and $96 \%$ specificity. As a positively expressed biomarker, nestin possesses technical advantages over INPP4B that make it a more ideal biomarker for identification of basal-like breast cancer. The comprehensive immunohistochemical biomarker survey presented in this study is a necessary step for determining an optimized surrogate immunopanel that best defines basal-like breast cancer in a practical and clinically accessible way. Modern Pathology (2013) 26, 1438-1450; doi:10.1038/modpathol.2013.97; published online 24 May 2013
\end{abstract}

Keywords: basal-like breast cancer; biomarker; gene expression profiling; immunohistochemistry; INPP4B; molecular subtype; nestin

For many years pathologists have recognized biological heterogeneity among breast cancers. Since the pioneering gene expression profile studies by Perou and colleagues that identified intrinsic subtypes of invasive carcinoma, ${ }^{1}$ the concept of breast cancer as a collection of different diseases has gained

Correspondence: Professor TO Nielsen, MD, PhD, FRCPC, Department of Anatomical Pathology, JP1502-855W 12th Avenue, Vancouver, BC, Canada V5Z 1M9.

E-mail: torsten@mail.ubc.ca

Received 11 March 2013; revised 1 May 2013; accepted 2 May 2013; published online 24 May 2013 widespread acceptance. ${ }^{2-6}$ Subsequent studies have confirmed that the five intrinsic molecular subtypes (luminal A, luminal B, HER2-enriched, basal-like and normal-like) possess distinct etiologies and clinicopathologic features with implications for treatment selection. ${ }^{1,7-12}$ Of particular relevance to patient management, the 'basallike' subtype comprises $\sim 15 \%$ of all invasive breast cancers and is responsible for a disproportionately high number of metastatic breast cancer cases and breast cancer-related deaths. ${ }^{13,14}$ This aggressive subtype is also associated with early age of onset, ${ }^{15-18}$ BRCA-related hereditary cancers $^{19-22}$ 
and has a particularly high incidence in women of African ethnicity. ${ }^{23-25}$ Despite its characteristically poor prognosis and resistance to established molecularly targeted therapies (eg, tamoxifen, aromatase inhibitors and trastuzumab), basal-like breast cancer is usually a diagnosis of exclusion in the clinical setting, based on lack of expression of hormone receptors and HER2. ${ }^{14,26}$ With limited therapeutic options, cytotoxic chemotherapy is the principal systemic treatment for women with this type of breast cancer.

At present, microarray-based gene expression profiling technologies are not practical for hospital diagnostic laboratories and routine analysis of patient specimens. In fact, the relatively high cost and complexities associated with sample preparation, assay and data analysis by gene expression profiling have resulted in few published reports on basal-like breast cancer using this gold standard for its identification. ${ }^{27}$ Most studies characterizing this subtype have performed investigations using formalin-fixed paraffin-embedded tissue specimens, typically obtained from clinical biopsy and excision samples found in pathology department archives. With immunohistochemistry as a universally available and inexpensive technique for analysis of formalin-fixed paraffin-embedded tissue, the literature has become dominated by the use of immunohistochemical surrogate definitions for basal-like breast cancer, most commonly the 'triplenegative phenotype' (TNP; characterized by the lack of expression of ER, PR and HER2), ${ }^{26}$ a basal cytokeratin definition (characterized by positive expression of basal cytokeratins 5, 14 and/or $17)^{20,28,29}$ or the immunopanel proposed in Nielsen et $a l^{14}$ (negative ER and HER2 but positive expression of CK5/6 and/or EGFR, later modified to a 5-marker immunopanel with inclusion of negative expression of PR), the latter identifying wider prognostic differences than TNP. ${ }^{16}$ However, against gene expression-based subtype assignment originally used to identify basal-like breast cancer, these immunohistochemical surrogates possess only moderate accuracy, with $76-79 \%$ sensitivity and $72-100 \%$ specificity. ${ }^{14,30}$

The past few years have seen a plethora of biomarkers described as having an association with the basal-like or triple-negative phenotypes. ${ }^{31,32}$ Only some have been validated on independent series, very few have been compared with a gene expression gold standard, and no study has compared large numbers of these candidate biomarkers in parallel in a single validation series. In line with current pathology practices that rely on immunohistochemistry and concurrent morphological examination, we sought to evaluate 72 proposed basal-like biomarkers, drawn from recent gene expression profile data and published literature, on sections from the same breast cancer tissue microarray in which intrinsic subtype has been assigned by a PAM50 gene expression profile assay. ${ }^{33,34}$ In doing so we sought to identify the best individual immunohistochemical biomarkers for this aggressive form of breast cancer.

\section{Materials and methods}

\section{Tissue Microarray Construction and PAM50 Molecular Subtype Assignment}

Breast cancer tissue microarrays were constructed from archival tumor blocks of 137 high-grade patients, who received surgical intervention at Washington University and Barnes-Jewish Hospital in St Louis from 1997 to 2003, as previously described. ${ }^{35}$ Samples (both direct consent and waived consent) were obtained from the Alvin J. Siteman Cancer Center Tissue Procurement Core facility according to an Institutional Review Boardapproved protocol. Duplicate 0.6-mm cores were extracted from each tumor block and transferred to the recipient tissue microarray block. Sample preparation and processing for PAM50 gene expression profiling using qRT-PCR from paraffin cores is described in Cheang et $a l^{36}$ and Nielsen et al. ${ }^{34}$ Of 137 cases, 127 were successfully assigned an intrinsic molecular subtype (basal-like, HER2enriched, luminal A, luminal B or normal-like). Excluding duplicate cases and the normal-like subtype from analysis, the remaining 122 samples consisted of 42 basal-like and 80 non-basal-like breast cancers (58 luminals and 22 HER2-enriched). Details of the PAM50 qRT-PCR subtype predictor are provided in Parker et al. ${ }^{33}$ This study was approved by the Clinical Research Ethics Board of the University of British Columbia and the British Columbia Cancer Agency.

\section{Immunohistochemical Staining and Scoring}

Seventy-two biomarkers were drawn from gene expression profile data and a survey of published literature performed in June 2011 (Table 1). Antibodies suitable for application on formalin-fixed paraffin-embedded tissue samples were acquired for 61 of 72 proposed biomarkers. Two EGFR antibodies were included in the analysis. Manual EGFR immunostaining was performed according to the PharmDX kit manufacturer's instructions (Dako Cytomation, Carpinteria, CA, USA). A rabbit monoclonal antibody for EGFR (Epitomics, Burlingame, CA, USA) was applied using a Discovery XT autoimmunostainer (Ventana Medical Systems, Tucson, AZ, USA). The Epitomics anti-EGFR possessed more consistent staining and superior ease of interpretation-in addition to the advantage of automated application-than the Dako PharmDX anti-EGFR. Thus, the Epitomics anti-EGFR was used for all immunohistochemical subtype definitions that included EGFR. An aliquot of anti-EZH2 was graciously provided by Dr Gulisa Turashvili 
Table 1 Antibody details for biomarkers that produced technically satisfactory immunostaining for scoring on the breast cancer tissue microarray ( $n=47$; including two EGFR antibodies)

\begin{tabular}{|c|c|c|c|c|c|c|}
\hline Antigen & Antibody type & Source & Clone & Dil. & Scoring system & Positive/n (\%) \\
\hline$\alpha \mathrm{BC}^{* 38-41}$ & Mouse mAb & Stressgen & 1B6.1-3G4 & $1 / 20$ & Neg vs any staining & 19/99 (19.2) \\
\hline Anillin ${ }^{33,42}$ & $\mathrm{pAb}$ & Bethyl Labs & & $1 / 100$ & Staining in $<10 \%$ vs $\geq 10 \%$ & $54 / 103(52.4)$ \\
\hline CAIX $^{43,44}$ & pAb & Santa Cruz & & $1 / 25$ & Neg vs any staining & $19 / 108(17.6)$ \\
\hline CAV1 ${ }^{45-49}$ & $\mathrm{pAb}$ & BD Biosciences & & $1 / 250$ & Staining in $<10 \%$ vs $\geq 10 \%$ & 29/104 (27.8) \\
\hline $\mathrm{CAV} 2^{48,50}$ & Mouse mAb & BD Biosciences & 65 & $1 / 50$ & Neg vs any staining & $8 / 105(7.6)$ \\
\hline CD $44^{51-54}$ & Rabbit mAb & Abcam & EPR1013Y & $1 / 25$ & Allred score system & $46 / 103(44.6)$ \\
\hline CD $44 v 6^{55-57}$ & Mouse mAb & BenderMed & VFF48 & $1 / 500$ & Staining in $<25 \%$ vs $\geq 25 \%$ & $67 / 108(62.0)$ \\
\hline C-Kit*14,58,59 & $\mathrm{pAb}$ & Dako & & $1 / 200$ & Any staining vs strong in $\geq 20 \%$ & 16/95 (16.8) \\
\hline CLDN4*60-62 & Mouse mAb & Zymed & $3 \mathrm{E} 2 \mathrm{C} 1$ & $1 / 50$ & Multiplicative quickscore & $41 / 101(40.6)$ \\
\hline Cyclin $E^{* 19,63}$ & Mouse mAb & Neomarkers & 13A3 & $1 / 10$ & Staining in $<10 \%$ vs $\geq 10 \%$ & 49/107 (45.7) \\
\hline CK5 ${ }^{* 20,64-67}$ & Mouse mAb & Thermo & XM26 & $1 / 25$ & Neg vs any staining & $30 / 96(31.3)$ \\
\hline CK5/6*14,68 & Mouse mAb & Zymed & $\mathrm{D} 5 / 16 \mathrm{~B} 4$ & $1 / 100$ & Neg vs any staining & $28 / 111(25.2)$ \\
\hline CK $14^{* 20,28,69,70}$ & Mouse mAb & Santa Cruz & LL002 & $1 / 100$ & Neg vs any staining & $10 / 106(9.4)$ \\
\hline CK $17^{* 67,69}$ & Mouse mAb & Dako & E3 & $1 / 50$ & Neg vs any staining & $21 / 94(22.3)$ \\
\hline $\mathrm{EGFR} * 14,24,58,71,72$ & Mouse mAb & Dako PharmDX & 2-18C9 & Pre-dil & Neg vs any staining & $19 / 104(18.3)$ \\
\hline EGFR*14,24,58,71,72 & Rabbit mAb & Epitomics & EP22 & $1 / 50$ & Neg vs any staining & $28 / 105(26.6)$ \\
\hline $\mathrm{ER}^{* 14,73}$ & Rabbit mAb & Thermo & SP1 & $1 / 25$ & Staining in $<1 \%$ vs $\geq 1 \%$ & $53 / 112(47.3)$ \\
\hline $\mathrm{EZH} 2^{74-78}$ & Mouse mAb & BD Biosc & 11 & $1 / 50$ & Staining in $<5 \%$ vs $\geq 5 \%$ & $76 / 102(74.5)$ \\
\hline FABP $7^{79-81}$ & Polyclonal & Abcam & & $1 / 100$ & Staining in $<10 \%$ vs $\geq 10 \%$ & $52 / 107(48.5)$ \\
\hline Fascin $* 82-84$ & Mouse mAb & Dako & $55 \mathrm{~K}-2$ & $1 / 100$ & Neg vs any staining & $27 / 108(25.0)$ \\
\hline FOXC1 ${ }^{33,85,86}$ & $\mathrm{pAb}$ & LifeSpan Biosciences & & $1 / 50$ & Neg vs any staining & $27 / 108(25.0)$ \\
\hline $\mathrm{HER}^{87}$ & Rabbit mAb & Neomarkers & SP3 & $1 / 500$ & Binarized with FISH correction & $12 / 104(11.5)$ \\
\hline IMP3 ${ }^{* 88-91}$ & Mouse mAb & Dako & 69.1 & $1 / 50$ & Neg vs any staining & $9 / 105(8.6)$ \\
\hline INPP4B $* 92-94$ & Rabbit mAb & Epitomics & EPR3108Y & $1 / 50$ & Staining in $\leq 5 \%$ vs $>5 \%$ & $23 / 106(21.7)$ \\
\hline Integrin $\beta 4^{95}$ & Rabbit mAb & eBiosciences & 439-9B & $1 / 25$ & Staining in $<5 \%$ vs $\geq 5 \%$ & $41 / 104(39.4)$ \\
\hline Ki67* & Rabbit mAb & Neomarkers & SP6 & $1 / 200$ & Staining in $<13.5 \%$ vs $\geq 13.5 \%$ & $72 / 111(64.8)$ \\
\hline Laminin $5^{96-98}$ & Mouse mAb & Dako & $4 \mathrm{G} 1$ & $1 / 25$ & Staining in $<5 \%$ vs $\geq 5 \%$ & $62 / 97(63.9)$ \\
\hline $\operatorname{Met}^{99-101}$ & & House-made & & & $\begin{array}{c}\text { Negative/weak/moderate staining } \\
\text { vs strong staining }>10 \%\end{array}$ & $41 / 120(34.1)$ \\
\hline Moesin $* 102,103$ & Mouse mAb & Sant & $38 / 87$ & $1 / 100$ & Neg Vs any staining & $35 / 100(35.0)$ \\
\hline Nestin $* 104-108$ & Mouse mAb & Santa Cruz & $10 \mathrm{c} 2$ & $1 / 50$ & Staining in $<1 \%$ vs $\geq 1 \%$ & $23 / 108(21.3)$ \\
\hline NGFR $* 109,110$ & Mouse mAb & Abcam & NGFR5 & $1 / 25$ & Neg $V s$ any staining & $8 / 103(7.8)$ \\
\hline p16*111-113 & Mouse mAb & $\mathrm{mtm}$ Laboratories & $\mathrm{E} 6 \mathrm{H} 4$ & $1 / 2$ & Staining in $\leq 80 \%$ vs $>80 \%$ & $36 / 95(37.8)$ \\
\hline $\mathrm{p} 27^{19,114}$ & Mouse mAb & BD Biosciences & 57 & $1 / 50$ & Staining in $<50 \%$ vs $\geq 50 \%$ & $27 / 106(25.4)$ \\
\hline p53*115-117 & Mouse mAb & Dako & DO-7 & $1 / 400$ & Staining in $<10 \%$ vs $\geq 10 \%$ & $33 / 105(31.4)$ \\
\hline p63 $3^{64,65,118}$ & Mouse mAb & CellMarque & $4 \mathrm{~A} 4$ & $1 / 200$ & Neg $v s$ any staining & $10 / 96(10.4)$ \\
\hline $\mathrm{P}-\mathrm{cad}^{* 65,70,119-122}$ & Mouse mAb & BD Biosciences & 56 & $1 / 20$ & $\begin{array}{l}\text { Weak staining in }<10 \% \text { vs } \\
\text { Any other staining }\end{array}$ & $55 / 105(52.3)$ \\
\hline P-gp 123 & Mouse mAb & Abcam & C494 & $1 / 50$ & Any Staining vs Strong in $\geq 20 \%$ & 34/95 (35.7) \\
\hline PPH3*124-127 & $\mathrm{pAb}$ & Upstate & & $1 / 100$ & Staining in $<1 \%$ vs $\geq 1 \%$ & $62 / 105(59.0)$ \\
\hline $\mathrm{PR}^{* 128}$ & Rabbit $\mathrm{mAb}$ & Neomarkers & SP2 & $1 / 200$ & Staining in $<1 \%$ vs $\geq 1 \%$ & $37 / 111(33.3)$ \\
\hline pS6rp & Rabbit mAb & Cell Signaling & 91B2 & $1 / 250$ & Staining in $<5 \%$ vs $\geq 5 \%$ & $46 / 95(48.4)$ \\
\hline PTEN & Rabbit mAb & Cell Signaling & 138G6 & $1 / 25$ & Neg vs any staining & 77/94 (81.9) \\
\hline S100A9*129-131 & $\mathrm{pAb}$ & Santa Cruz & & $1 / 100$ & Staining in $<$ median $v s \geq$ median & $35 / 105(33.3)$ \\
\hline Skp2*63,114,132 & Mouse mAb & Zymed & 2C8D9 & $1 / 25$ & Staining in $<10 \%$ vs $\geq 10 \%$ & $32 / 96(33.3)$ \\
\hline SMAD4 & Mouse mAb & Santa Cruz & B-8 & $1 / 50$ & Allred score system & $39 / 95(41.1)$ \\
\hline TRIM29* & Goat pAb & Santa Cruz & & $1 / 100$ & $\begin{array}{c}\text { Bkgd or lower in }<100 \% \text { vs } \\
\text { above bkgd }\end{array}$ & $36 / 97(37.1)$ \\
\hline VEGF-A ${ }^{133-135}$ & Mo & $\mathrm{L}$ & JH121 & $1 / 25$ & Staining in $<185$ vs $\geq 185$ & 59.0) \\
\hline Vimentin $^{70,96,136,137}$ & Mouse mAb & Zymed & V9 & $1 / 50$ & Staining in $<1 \%$ vs $\geq 1 \%$ & $18 / 100(18.0)$ \\
\hline
\end{tabular}

Abbreviations: bkgd, background; dil., dilution; mAb, monoclonal; pAb, polyclonal antibody.

Biomarkers that failed to progress to analysis due to lack of a commercial antibody demonstrated to work for IHC applications on breast tissue included: ALDH1, CD109, CD123, CD146, E2F-5, OATP2, Osteopontin, S100A2 and S100A7. Those that failed to progress due to nonspecific staining on controls tested in our laboratory included: Aurora A, Aurora B, CD68, CD280, CEP55, Chromogranin A, c-Myc, CXCR4, KNTC2, MELK, MIA, RAD51, Sox2, SPARC and YB-1. BRCA1 immunostaining results were excluded after mutational analysis performed by an external laboratory determined that nuclear staining was spurious, likely introduced by prolonged antibody storage. VEGFR2 showed discrepant staining relative to the positive control and was not subjected to further analysis.

*Biomarkers significantly associated with basal-like breast cancer after correction for multiple comparisons.

(BC Cancer Agency, Vancouver, BC, Canada). INPP4B was obtained from Epitomics. An antibody for Met was made in-house and previously stained by an external laboratory, ${ }^{35,37}$ generating the data utilized in the current study. During immunohistochemical optimization using standard laboratory staining protocols programmed into the Discovery XT auto-immunostainer, 15 of the 61 candidate immunohistochemical biomarkers demonstrated nonspecific staining on control tissues or tissue microarrays after multiple attempts with varying antibody dilutions and 
protocols. The remaining 46 were stained on $4 \mu \mathrm{m}$ sections of the above-described breast cancer tissue microarray. Stained slides were scanned using a BLISS system (Bacus Laboratories/Olympus America, Lombard, IL, USA), and a pathologist scored each biomarker using, wherever possible, the scoring system described in the original literature associating that biomarker with basal-like breast cancer (Table 1).

\section{Statistical Analysis}

PASW Statistics 18 for Windows (SPSS, 2009, Chicago, IL, USA, www.spss.com) was used to perform contingency table analyses. Pearson's $\chi^{2}$ analysis (or the Fisher's exact test, when appropriate) was used to compare biomarker expression in basal-like and non-basal-like cases defined by PAM50 gene expression profile. $P$-values were adjusted for multiple comparisons using a modified Bonferonni correction method previously described by Holm, ${ }^{138}$ after which $P<0.05$ defined statistical significance. Ninety-five percent confidence intervals (95\% CI) for sensitivity and specificity for each biomarker were generated in $\mathrm{R}$ version 2.11.1 (www.r-project.org) using a bootstrap methodology.

\section{Results}

\section{Tissue Microarray Staining}

Following antibody evaluation and optimization, immunostaining of 46 proposed biomarkers for basal-like breast cancer was technically satisfactory for scoring on the breast cancer tissue microarray (containing 42 basal-like and 80 non-basal like cases, as determined by PAM50 expression profile). Table 1 includes details of these antibodies and lists the number of cases available for analysis of each immunostain. Missing data reflects loss of cores from the tissue microarray section or exhaustion of tumor tissue in cores as sections went deeper into the tissue microarray block. Representative staining of each positively expressed basal-like breast cancer biomarker is illustrated in Figure 1. Described immunostains can be viewed in full through a



Figure 1 Representative staining of positively expressed basal-like biomarkers. 
digital image archive accessible via the website of the Genetic Pathology Evaluation Centre (www. gpecimage.ubc.ca).

\section{Immunohistochemical Interpretation and Univariate Analysis of Basal-Like Biomarkers}

After correction for multiple comparisons, 25 of these 46 proposed basal-like biomarkers (labeled by an asterisk in Table 1) were significantly associated with basal-like breast cancer. Sensitivity, specificity, odds ratio (OR) as well as raw $P$-values for each of these biomarkers are presented in Table 2 .

At an individual sensitivity of $92 \%$, Ki67 (based on the previously established $13.5 \%$ cutpoint $^{36}$ ) and phosphohistone-H3 (PPH3) were the most sensitive biomarkers for basal-like breast cancer. Ki67, a nuclear antigen expressed by proliferating cells, has been extensively characterized in the literature. ${ }^{139,140}$ PPH3, a lesser known marker of mitotic figures, ${ }^{126,141}$ lacks consistent established cutpoints that led to the adoption of a $1 \%$ cutpoint in the present study (corresponding to a commonly advocated cutpoint for ER). Of particular relevance to feasibility of clinical implementation, study investigators noted and confirmed that nuclear staining of PPH3 is strong, discrete and easy to interpret. ${ }^{127}$ Lymphocyte staining and cytoplasmic staining in tumor cells were occasionally observed. Similarly, in support of common surrogate panels for basal-like breast cancer, lack of ER or PR expression was also sensitive (92\%) for detection of basal-like breast cancer.
The biomarkers displaying the highest specificity $(100 \%)$ for basal-like breast cancer in this study were cytokeratin 14 (CK14), insulin-like growth factor mRNA binding protein-3 (IMP3) and nerve growth factor receptor (NGFR). However, this apparently perfect specificity came at the price of poor individual sensitivity, ranging from $22 \%$ to $27 \%$. Consistent with other basal cytokeratins, strong cytoplasmic and peri-membranous staining of CK14 was observed in tumor cells and the basal/ myoepithelial layer of normal breast epithelial elements (disregarded during scoring). IMP3 staining was cytoplasmic and predominantly of weak intensity, but present in most tumor cells of a positive core. Essentially no background staining was observed for IMP3, making it possible for a trained pathologist to distinguish the characteristic weak positive staining in tumor cells. NGFR staining was membranous but, unlike CK14 and IMP3 staining, was not restricted to basal-like tumor cells and basal/myoepithelial cells of normal breast, as it was also seen in nerves and in occasional stromal and endothelial cells.

Negative INPP4B (inositol polyphosphate-4-phosphatase, type II) staining possessed the best combination of sensitivity (61.1\%) and specificity (98.6\%) with the overall highest individual OR (108.4) among the biomarkers tested in this study, suggesting its absence may be the best single diagnostic immunohistochemical biomarker for basal-like breast cancer. Although different staining intensities were observed (Figure 2a), cytoplasmic staining of INPP4B was only scored as percent positive tumor cells then later binarized using a 5\% cutpoint.

Table 2 Test characteristics of statistically significant basal-like breast cancer biomarkers after correction for multiple comparisonsarranged by odds ratio (OR)

\begin{tabular}{|c|c|c|c|c|}
\hline Biomarker & Sensitivity (95\% CI) & Specificity (95\% CI) & $O R(95 \% C I)$ & Raw P-value \\
\hline INPP4B negative & $61.1(43.8-75.9)$ & $98.6(91.5-100)$ & $108.4(13.5-872.0)$ & $1.7 \mathrm{E}-12$ \\
\hline Nestin & $54.1(37.2-70.0)$ & $95.8(88.2-98.7)$ & $26.7(7.1-100.3)$ & $1.9 \mathrm{E}-09$ \\
\hline ER negative & $92.1(78.6-97.6)$ & $67.6(56.1-77.6)$ & $24.3(6.8-87.0)$ & $2.1 \mathrm{E}-09$ \\
\hline CK5 & $70.6(52.8-84.2)$ & $90.3(80.3-96.2)$ & $22.4(7.3-68.6)$ & $7.4 \mathrm{E}-10$ \\
\hline cKit & $42.4(25.6-59.4)$ & $96.8(88.2-100)$ & $22.1(4.6-106.1)$ & $2.9 \mathrm{E}-06$ \\
\hline p16 & $78.8(61.3-90.5)$ & $83.9(72.7-91.7)$ & $19.3(6.6-56.6)$ & $2.0 \mathrm{E}-09$ \\
\hline Fascin & $57.9(41.5-73.0)$ & $92.9(84.4-97.2)$ & $17.9(5.9-54.5)$ & $6.0 \mathrm{E}-09$ \\
\hline РPH3 & $91.7(77.8-97.5)$ & $58.0(45.9-69.2)$ & $15.2(4.2-54.3)$ & $3.5 \mathrm{E}-07$ \\
\hline Moesin & $71.4(53.3-84.4)$ & 84.6 (73.7-91.9) & $13.8(5.1-37.2)$ & $2.1 \mathrm{E}-08$ \\
\hline CK17 & $50.0(31.0-65.7)$ & $91.9(82.5-96.9)$ & $11.4(3.6-35.9)$ & $3.7 \mathrm{E}-06$ \\
\hline ki67 & $92.1(78.4-97.7)$ & $49.3(37.8-60.8)$ & $11.4(3.2-40.2)$ & $7.3 \mathrm{E}-06$ \\
\hline PR negative & $92.1(78.6-97.6)$ & $46.6(35.0-58.2)$ & $10.2(2.9-36.1)$ & $3.5 \mathrm{E}-05$ \\
\hline TRIM29 & $71.0(51.9-85.2)$ & $78.8(67.2-87.3)$ & $9.1(3.4-24.1)$ & $2.2 \mathrm{E}-06$ \\
\hline$\alpha$-B-crystallin & $41.2(25.0-58.3)$ & $92.3(83.3-97.0)$ & $8.4(2.7-26.3)$ & $5.9 \mathrm{E}-05$ \\
\hline S100A9 & $62.2(45.5-76.9)$ & $82.4(71.4-90.2)$ & 7.7 (3.1-19.1) & $3.8 \mathrm{E}-06$ \\
\hline CK5/6 & $50.0(32.6-64.9)$ & $87.7(78.1-93.9)$ & 7.1 (2.8-18.3) & $1.4 \mathrm{E}-05$ \\
\hline Skp2 & $60.6(42.4-76.0)$ & $81.0(69.4-89.1)$ & $6.5(2.6-16.7)$ & $4.1 \mathrm{E}-05$ \\
\hline EGFR (Epitomics) & $51.4(34.3-67.6)$ & $85.7(75.4-92.4)$ & $6.4(2.5-16.3)$ & $5.0 \mathrm{E}-05$ \\
\hline P-cadherin & $77.8(60.7-89.2)$ & $60.9(48.5-71.6)$ & $5.4(2.2-13.7)$ & $1.7 \mathrm{E}-04$ \\
\hline Claudin 4 & $63.9(46.4-78.6)$ & $72.3(60.0-82.3)$ & $4.6(1.9-11.0)$ & $3.9 \mathrm{E}-04$ \\
\hline Cyclin E & $69.4(51.9-82.9)$ & $66.2(54.4-76.4)$ & $4.5(1.9-10.6)$ & $4.7 \mathrm{E}-04$ \\
\hline p53 & $52.8(36.1-69.0)$ & $79.7(68.7-88.1)$ & $4.4(1.8-10.6)$ & $6.6 \mathrm{E}-04$ \\
\hline CK14 & $27.0(13.9-43.2)$ & 100 & - & $1.1 \mathrm{E}-05$ \\
\hline IMP3 & $25.0(11.8-40.6)$ & 100 & - & $3.1 \mathrm{E}-05$ \\
\hline NGFR & $22.2(10.3-38.1)$ & 100 & - & $1.3 \mathrm{E}-04$ \\
\hline
\end{tabular}


a

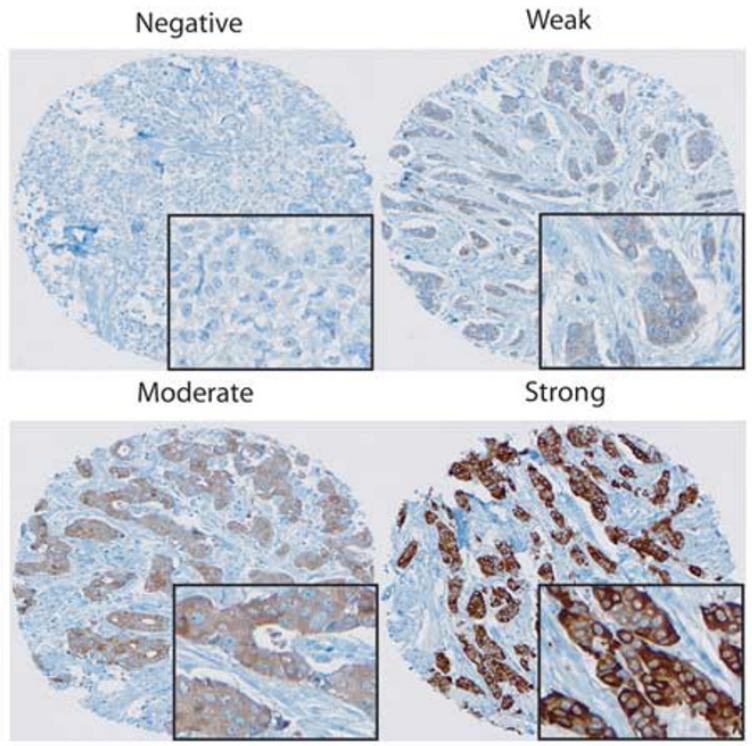

b

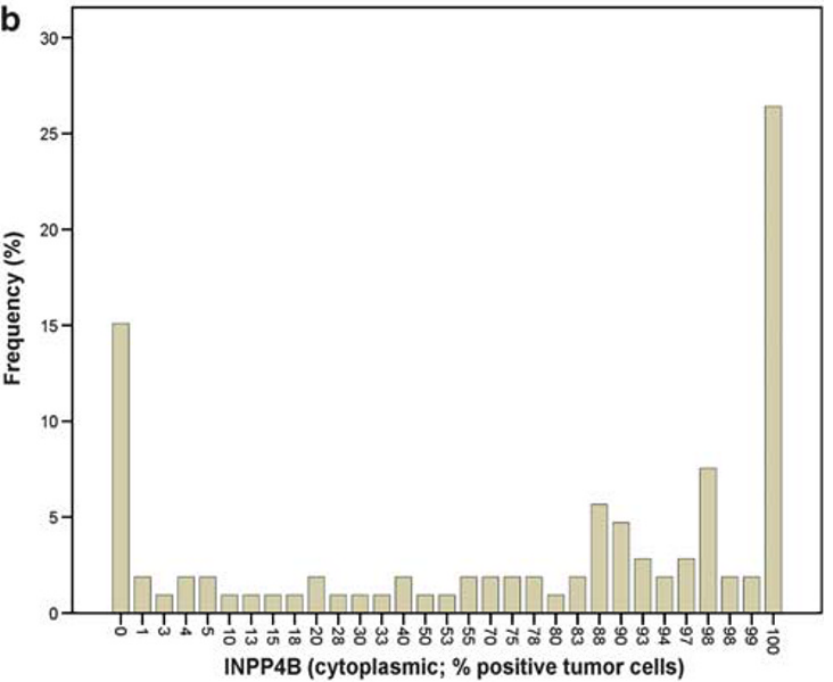

Figure 2 Immunohistochemical analysis of INPP4B in breast cancer. (a) The majority of cases expressing INPP4B demonstrated staining in most tumor cells regardless of staining intensity. (b) The frequency distribution of percent positive tumor cells regardless of INPP4B staining intensity confirmed this observation.

Very minimal background staining was noted. The pattern of INPP4B expression was observed to be predominantly dichotomous, with more than half of cases having all-or-none staining in tumor cells (Figure 2b).

Other single biomarkers with a relatively favorable OR include nestin (using a 1\% cutpoint), negative ER staining (using a 1\% cutpoint), CK5 (notably more sensitive than older CK5/6 antibodies; Table 2) and c-kit. Thus, the best positively expressed immunohistochemical biomarkers for basal-like breast cancer are nestin and CK5, both representing intermediate filaments belonging to a category of proteins that are relatively abundant and stably expressed-two features that are technically advantageous for immunohistochemical analyses.

\section{Discussion}

Gene expression profiling-based technologies originally used to identify basal-like breast cancer are not widely accessible in daily practice. DNA microarray-based testing platforms currently lack the robustness and cost-efficiency required for routine clinical use. Surrogate immunohistochemical definitions for basal-like breast cancer, despite moderate sensitivity and specificity, have been more frequently employed by both the research and medical communities. Building on the clinical ER/ PR/HER2 TNP, basal cytokeratin definitions and the combined immunopanel described in our previous work, ${ }^{14,16}$ a large and evolving body of research has since described additional biomarkers for basal-like breast cancer (reviewed in Choo et $a l^{31}$ ).

Validation of proposed biomarkers against a gold standard is a necessary step to identify the most useful biomarkers that can best define the intrinsic molecular subtypes of breast cancer by immunohistochemistry. The development of the PAM50 assay, a gene expression assay applicable to formalinfixed paraffin-embedded blocks, ${ }^{33,34}$ now greatly facilitates such endeavors. Specifically, this 50gene bioclassifier stratifies breast cancers into prognostic groups that can be used to aid clinicians in making treatment decisions. ${ }^{33,34,142}$ Furthermore, the PAM50 assay identifies breast cancer intrinsic subtypes (luminal A, luminal B, HER2-enriched or basal-like) with prognostic and predictive implications. ${ }^{142,143}$ This study presents an immunohistochemical assessment of several dozen published biomarkers of the aggressive basal-like subtype of breast cancer in a cohort of molecularly defined breast cancer specimens.

On the basis of OR, loss of INPP4B expression $(\mathrm{OR}=108.4,61.1 \%$ sensitivity and $98.6 \%$ specificity) is the immunohistochemical assay that is most strongly associated with basal-like breast cancer among the 46 biomarkers tested. This class II phosphatase is one of the many players involved in the negative regulation of phosphatidylinositol signaling, a pathway of particular interest for targeted therapies in basal-like and triple-negative breast cancers. ${ }^{144-148}$ Located on chromosome $4 \mathrm{q} 31.21$, the INPP $4 B$ locus is commonly deleted in basal-like breast cancers and cell lines. ${ }^{92-94,149-151}$ Previous studies characterizing INPP4B as a tumor suppressor were primarily focused at the genetic level; however, Gewinner et $a l^{93}$ recently demonstrated successful immunohistochemical analysis of INPP4B and correlation between loss of INPP4B expression and decreased overall breast cancer survival.

Nonetheless, relying on lack of expression of a biomarker for identification of basal-like breast 
cancer cases can be misleading as negative staining can be caused by technical problems at any of the several steps. For instance, antigen fading was an issue that we encountered with the INPP4B antibody when applied to tissue microarray cohorts consisting of previously frozen, archival formalin-fixed paraffin-embedded pathology specimens collected more than 25 years ago (data not shown). Conversely, nestin-a positive biomarker for basallike breast cancer-possessed the second highest odd ratio $(\mathrm{OR}=28.7,54.1 \%$ sensitivity and $95.8 \%$ specificity) among the 46 biomarkers surveyed. This type VI intermediate filament is an established marker of neural progenitor cells, ${ }^{152,153}$ yet several studies have described its expression in the basal/ myoepithelial layer of the mammary gland and in tumor cells of suspected basal-like and triplenegative breast cancer cases. ${ }^{104-108,154}$ Parry et al ${ }^{106}$ reported nestin positivity in 15 of 22 (68\%) basallike cases (as defined by the Nielsen et $a 1^{14}$ immunohistochemical definition) as compared with 3 of 117 (2\%) non-basal-like cases. Similarly, Liu et $a 1^{108}$ detected nestin expression in 9 of 21 (57\%) TNPs but only 12 of 129 (9\%) non-TNPs. In this study, nestin displayed positive immunohistochemical expression in 20 of 36 (55\%) cases defined as basal-like by expression profile, but only 3 of $72(4 \%)$ non-basal-like cases. The observed consistency of nestin immunostaining and interpretation across different studies may reflect good antigen stability in clinical samples, typical of structural proteins.

Ki67 and PPH3, both markers of proliferation associated with poor prognosis and basal-like/triplenegative breast cancer, ${ }^{124,126,127,141,155}$ possessed the highest sensitivity $(\sim 92 \%)$ for the basal-like subtype in the present study. Nevertheless, neither Ki67 nor PPH3 is particularly specific for the basal-like subtype, hardly surprising given that luminal B and HER2-enriched breast cancers are also characterized by strong proliferation signatures. ${ }^{1,3,7}$ CK14, IMP3 and NGFR had the highest specificity (100\%) for basal-like breast cancer but this came at the significant expense of sensitivity, which, in line with published observations, ${ }^{84,109}$ ranged from $22 \%$ to $27 \%$.

Given that highly specific biomarkers had low sensitivity while highly sensitive biomarkers suffered low specificity, a multi-marker immunopanel rather than a single biomarker might be more useful to account for phenotypic heterogeneity and increase overall sensitivity for detection. ${ }^{156,157}$ Preferably, such a panel would also exhibit high sensitivity and specificity with a limited, practical number of biomarkers. ${ }^{158}$ Interestingly, as individual biomarkers for basal-like breast cancer, INPP4B (61\% sensitivity, 99\% specificity) and nestin (54\% sensitivity, 96\% specificity) showed comparable sensitivities and specificities to existing multi-marker definitions, such as the TNP (83\% sensitive, $87 \%$ specific) and the Nielsen et al ${ }^{14}$ definition (67\% sensitive, 93\% specific). A 2-marker panel for identification of basal-like breast carcinomas comprised of INPP4B negativity and/or nestin positivity was observed to have $83 \%$ sensitivity and $96 \%$ specificity. Similarly, a 2-marker panel of INPP4B and CK5, another top basal-like biomarker from the current survey that is already an established immunohistochemical marker in diagnostic laboratories, possessed $83 \%$ sensitivity and $91 \%$ specificity. However, to avoid overoptimistic results due to over-fitting, fair comparisons against existing immunopanels and any attempts to determine a superior surrogate panel that best defines basal-like breast cancer need to be performed on a series independent from the one used herein to identify the best biomarkers, and ideally by independent research groups. Our available large tissue microarray series (most recently described in Mehta et $a 1^{159}$ ), designed for biomarker correlations with long-term outcomes, appears unsuitable for this task due to the antigen-fading issue around INPP4B, suggesting a more contemporary series might be better suited for such work.

As with all reported statically significant basallike biomarkers described above or listed in Table 2, large confidence intervals for OR values were observed, indicating that results should be interpreted with caution due to the limited sample size. As pointed out by Pepe et $a{ }^{160}{ }^{160}$ the independent contribution of a biomarker to classification accuracy can be negligible despite a strong association with disease status (in this case, basallike as opposed to non-basal-like breast cancer). However, in conjunction with reported sensitivity and specificity values, all lowest confidence interval values remain above the null value $(\mathrm{OR}=1)$, supporting a true association between tested biomarkers and basal-like breast cancer. ${ }^{161}$

Although great strides have been made in automated immunostaining and antigen retrieval techniques, as well as commercialization of antibodies for an ever-growing list of antigens, it still remains to be determined whether or not immunohistochemistry is entirely up to task for recapitulating gene expression profile analyses. Subject to data reduction and statistical model building techniques on a series independent from the one used herein, the results of this comprehensive immunohistochemical survey may be able to contribute to the development of a clinically practical multi-marker immunopanel that best defines basal-like breast cancer in an inexpensive and widely accessible way. ${ }^{162,163}$ Followed by rigorous evaluation of classification accuracy and validation on large independent data sets, application of such an assay in retrospective analyses and prospective clinical trials will help to accurately identify basal-like breast cancer cases, ultimately facilitating development of much needed therapies for breast cancer patients with this particularly aggressive form of the disease. 


\section{Acknowledgements}

We are very grateful for the technical assistance of Krista Marcon and Erika Mehl during their time at the Genetic Pathology Evaluation Centre. We would also thank Samuel Leung for his statistical advice. Hann-Hsiang Chao and Xiaping $\mathrm{He}$ of the Perou lab provided helpful input during optimization of INPP4B immunohistochemistry. We would also thank Dr Samuel Aparicio for providing valuable discussion and insight on the gene expression of INPP4B in breast cancer. This work was supported by NIH SPECS grant (U01 CA114722-01), an unrestricted educational grant from Sanofi-Aventis Canada, a studentship from CIHR to JRW, a Senior Scholar award to TON from the Michael Smith Foundation for Health Research and a grant from the Canadian Breast Cancer Foundation (BC/Yukon Division).

\section{Disclosure/conflict of interest}

MJE, CMP, and PSB hold shares in, and TON has received consultant fees from, Bioclassifier LLC. Bioclassifier LLC holds the patent rights to the PAM50 test, which has been licensed to Nanostring Technologies. Nanostring Technologies is currently working to commercialize the PAM50 test in a format different from the research test used in the paper. Neither Bioclassifier LLC nor Nanostring Technologies financed any aspects of the current manuscript. PAM50 is an open source bioinformatics approach that can be applied to data generated with a variety of research-use-only platforms (in this case, a PCR-based platform different from the clinical assay being commercialized by Nanostring Technologies). The remaining authors declare no conflict of interest.

\section{References}

1 Perou CM, Sorlie T, Eisen MB, et al. Molecular portraits of human breast tumours. Nature 2000;406: 747-752.

2 Geyer F, Marchio C, Reis-Filho J. The role of molecular analysis in breast cancer. Pathology 2009; 41:77-88.

3 Fan C, Oh DS, Wessels L, et al. Concordance among gene-expression-based predictors for breast cancer. N Engl J Med 2006;355:560-569.

4 Simpson PT, Reis-Filho JS, Gale T, et al. Molecular evolution of breast cancer. J Pathol 2005;205: 248-254.

5 Carey LA. Through a glass darkly: advances in understanding breast cancer biology, 2000-2010. Clin Breast Cancer 2010;10:188-195.

6 Cummings MC, Chambers R, Simpson PT, et al. Molecular classification of breast cancer: is it time to pack up our microscopes? Pathology 2011;43:1-8.
7 Perou CM, Børresen-Dale AL. Systems biology and genomics of breast cancer. Cold Spring Harb Perspect Biol 2011;3:a003293.

8 Sorlie T, Perou CM, Tibshirani R, et al. Gene expression patterns of breast carcinomas distinguish tumor subclasses with clinical implications. Proc Natl Acad Sci USA 2001;98:10869-10874.

9 Sorlie T, Tibshirani R, Parker J, et al. Repeated observation of breast tumor subtypes in independent gene expression data sets. Proc Natl Acad Sci USA 2003;100:8418-8423.

10 Kennecke $\mathrm{H}$, Yerushalmi $\mathrm{R}$, Woods $\mathrm{R}$, et al. Metastatic behavior of breast cancer subtypes. J Clin Oncol 2010;28:3271-3277.

11 Voduc D, Cheang MCU, Tyldesley S, et al. Breast cancer subtypes and the risk of local and regional relapse. J Clin Oncol 2010;28:1684-1691.

12 Desmedt C, Haibe-Kains B, Wirapati $\mathrm{P}$, et al. Biological processes associated with breast cancer clinical outcome depend on the molecular subtypes. Clin Cancer Res 2008;14:5158-5165.

13 Carey LA. Directed therapy of subtypes of triplenegative breast cancer. Oncologist 2010;15:49-56.

14 Nielsen TO, Hsu FD, Jensen K, et al. Immunohistochemical and clinical characterization of the basal-like subtype of invasive breast carcinoma. Clin Cancer Res 2004;10:5367-5374.

15 Perou CM. Molecular stratification of triple-negative breast cancers. Oncologist 2010;15:61-70.

16 Cheang MCU, Voduc D, Bajdik C, et al. Basal-like breast cancer defined by five biomarkers has superior prognostic value than triple-negative phenotype. Clin Cancer Res 2008;14:1368-1376.

17 Yehiely F, Moyano JV, Evans JR, et al. Deconstructing the molecular portrait of basal-like breast cancer. Trends Mol Med 2006;12:537-544.

18 Millikan RC, Newman B, Tse CK, et al. Epidemiology of basal-like breast cancer. Breast Cancer Res Treat 2008;109:123-139.

19 Foulkes WD, Brunet J, Stefansson IM, et al. The prognostic implication of the basal-like (cyclin ehigh/p27low/p53 + /glomeruloid-microvascular-proliferation + ) phenotype of BRCA1related breast cancer. Cancer Res 2004;64:830-835.

20 Laakso M, Loman N, Borg A, et al. Cytokeratin 5/14positive breast cancer: true basal phenotype confined to BRCA1 tumors. Mod Pathol 2005; 18:1321-1328.

21 Tischkowitz MD, Foulkes WD. The basal phenotype of BRCA1-related breast cancer: past, present and future. Cell Cycle 2006;5:963-967.

22 Arnes JB, Begin LR, Stefansson I, et al. Expression of epidermal growth factor receptor in relation to BRCA1 status, basal-like markers and prognosis in breast cancer. J Clin Pathol 2009;62:139-146.

23 Carey LA, Perou CM, Livasy CA, et al. Race, breast cancer subtypes, and survival in the Carolina Breast Cancer Study. JAMA 2006;295:2492-2502.

24 Nalwoga H. Expression of EGFR and c-kit is associated with the basal-like phenotype in breast carcinomas of African women. Acta Pathol Microbiol Immunol Scandinavica 2008;116:515-525.

25 Parise CA, Bauer KR, Caggiano V. Variation in breast cancer subtypes with age and race/ethnicity. Crit Rev Oncol Hematol 2010;76:44-52.

26 Badve S, Dabbs DJ, Schnitt SJ, et al. Basal-like and triple-negative breast cancers: a critical review with 
an emphasis on the implications for pathologists and oncologists. Mod Pathol 2011;24:157-167.

27 Bastien RR, Rodriguez-Lescure A, Ebbert MT, et al. PAM50 breast cancer subtyping by RT-qPCR and concordance with standard clinical molecular markers. BMC Med Genomics 2012;5:44-56.

28 Potemski P, Kusinska R, Watala C, et al. Prognostic relevance of basal cytokeratin expression in operable breast cancer. Oncology 2005;69:478-485.

29 Rakha EA, Putti TC, El-Rehim DMA, et al. Morphological and immunophenotypic analysis of breast carcinomas with basal and myoepithelial differentiation. J Pathol 2006;208:495-506.

30 Bertucci F, Finetti P, Cervera N, et al. How basal are triple-negative breast cancers? Int $\mathrm{J}$ Cancer 2008;123:236-240.

31 Choo JR, Nielsen TO. Biomarkers for basal-like breast cancer. Cancers 2010;2:1040-1065.

32 Toft DJ, Cryns VL. Minireview: basal-like breast cancer: from molecular profiles to targeted therapies. Mol Endocrinol 2010;25:199-211.

33 Parker JS, Mullins M, Cheang MCU, et al. Supervised risk predictor of breast cancer based on intrinsic subtypes. J Clin Oncol 2009;27:1160-1167.

34 Nielsen TO, Parker JS, Leung S, et al. A comparison of PAM50 intrinsic subtyping with immunohistochemistry and clinical prognostic factors in tamoxifen-treated estrogen receptor positive breast cancer. Clin Cancer Res 2010;16:5222-5232.

35 Graveel CR, DeGroot JD, Su Y, et al. Met induces diverse mammary carcinomas in mice and is associated with human basal breast cancer. Proc Natl Acad Sci USA 2009;106:12909-12914.

36 Cheang MCU, Chia SK, Voduc D, et al. Ki67 index, HER2 status, and prognosis of patients with luminal B breast cancer. J Natl Cancer Inst 2009;101:736-750.

37 Knudsen BS, Zhao P, Resau J, et al. A novel multipurpose monoclonal antibody for evaluating human c-met expression in preclinical and clinical settings. App Immunohisto Mol Morph 2009;17:57-67.

38 Moyano JV, Evans JR, Chen F, et al. AlphaB-crystallin is a novel oncoprotein that predicts poor clinical outcome in breast cancer. J Clin Invest 2006;116: 261-270.

39 Sitterding SM, Wiseman WR, Schiller CL, et al. AlphaB-crystallin: a novel marker of invasive basallike and metaplastic breast carcinomas. Ann Diagn Pathol 2008;12:33-40.

40 Ivanov O, Chen F, Wiley E, et al. $\alpha \mathrm{B}$-crystallin is a novel predictor of resistance to neoadjuvant chemotherapy in breast cancer. Breast Cancer Res Treat 2008;111:411-417.

41 Chan SK, Lui PCW, Tan PH, et al. Increased alpha-Bcrystallin expression in mammary metaplastic carcinomas. Histopathology 2011;59:247-255.

42 Hall PA, Todd CB, Hyland PL, et al. The septinbinding protein anillin is overexpressed in diverse human tumors. Clin Cancer Res 2005;11:6780-6786.

43 Chia SK, Wykoff CC, Watson PH, et al. Prognostic significance of a novel hypoxia-regulated marker, carbonic anhydrase IX, in invasive breast carcinoma. J Clin Oncol 2001;19:3660-3668.

44 Tan EY, Yan M, Campo L, et al. The key hypoxia regulated gene CAIX is upregulated in basal-like breast tumours and is associated with resistance to chemotherapy. $\mathrm{Br} \mathrm{J}$ Cancer 2009;100:405-411.
45 Pinilla S, Honrado E, Hardisson D, et al. Caveolin-1 expression is associated with a basal-like phenotype in sporadic and hereditary breast cancer. Breast Cancer Res Treat 2006;99:85-90.

46 Savage K, Lambros MBK, Robertson D, et al. Caveolin 1 is overexpressed and amplified in a subset of basal-like and metaplastic breast carcinomas: a morphologic, ultrastructural, immunohistochemical, and in situ hybridization analysis. Clin Cancer Res 2007;13:90-101.

47 Liedtke C, Kersting C, Burger H, et al. Caveolin-1 expression in benign and malignant lesions of the breast. World J Surg Oncol 2007;5:110-118.

48 Elsheikh SE, Green AR, Rakha EA, et al. Caveolin 1 and caveolin 2 are associated with breast cancer basal-like and triple-negative immunophenotype. Br J Cancer 2008;99:327-334.

49 Patani N, Martin LA, Reis-Filho JS, et al. The role of caveolin-1 in human breast cancer. Breast Cancer Res Treat 2012;131:1-15.

50 Savage K, Leung S, Todd S, et al. Distribution and significance of caveolin 2 expression in normal breast and invasive breast cancer: an immunofluorescence and immunohistochemical analysis. Breast Cancer Res Treat 2008;110:245-256.

51 Klingbeil P, Natrajan R, Everitt G, et al. CD44 is overexpressed in basal-like breast cancers but is not a driver of 11p13 amplification. Breast Cancer Res Treat 2009;120:95-109.

52 Ricardo S, Vieira AF, Gerhard R, et al. Breast cancer stem cell markers CD44, CD24 and ALDH1: expression distribution within intrinsic molecular subtype. J Clin Pathol 2011;64:937-946.

53 de Beça FF, Caetano P, Gerhard R, et al. Cancer stem cells markers CD44, CD24 and ALDH1 in breast cancer special histological types. J Clin Pathol 2013;66:187-191.

54 Olsson E, Honeth G, Bendahl PO, et al. CD44 isoforms are heterogeneously expressed in breast cancer and correlate with tumor subtypes and cancer stem cell markers. BMC Cancer 2011;11: 418-431.

$55 \mathrm{Yu}$ P, Zhou L, Ke W, et al. Clinical significance of pAKT and CD44v6 overexpression with breast cancer. J Cancer Res Clin Oncol 2010;136: 1283-1292.

56 Shah NG, Trivedi TI, Vora HH, et al. CD44v6 expression in primary breast carcinoma in western India: a pilot clinicopathologic study. Tumori 2010;96:971-977.

57 Afify A, Purnell P, Nguyen L. Role of CD44s and CD44v6 on human breast cancer cell adhesion, migration, and invasion. Exp Mol Pathol 2009;86:95-100.

58 Tsuda H, Morita D, Kimura M, et al. Correlation of KIT and EGFR overexpression with invasive ductal breast carcinoma of the solid-tubular subtype, nuclear grade 3, and mesenchymal or myoepithelial differentiation. Cancer Sci 2005;96:48-53.

59 Azoulay S, Lae M, Freneaux P, et al. KIT is highly expressed in adenoid cystic carcinoma of the breast, a basal-like carcinoma associated with a favorable outcome. Mod Pathol 2005;18:1623-1631.

60 Lanigan F, McKiernan E, Brennan DJ, et al. Increased claudin-4 expression is associated with poor prognosis and high tumour grade in breast cancer. Int J Cancer 2009;124:2088-2097. 
61 Kulka J, Szász A, Németh Z, et al. Expression of tight junction protein claudin-4 in basal-like breast carcinomas. Pathol Oncol Res 2009;15:59-64.

62 Blanchard A, Skliris G, Watson P, et al. Claudins 1, 3, and 4 protein expression in ER negative breast cancer correlates with markers of the basal phenotype. Virchows Arch 2009;454:647-656.

63 Voduc D, Nielsen TO, Cheang MC, et al. The combination of high cyclin E and Skp2 expression in breast cancer is associated with a poor prognosis and the basal phenotype. Hum Pathol 2008;39: 1431-1437.

64 Ribeiro-Silva A, Ramalho LNZ, Garcia SB, et al. p63 correlates with both BRCA1 and cytokeratin 5 in invasive breast carcinomas: further evidence for the pathogenesis of the basal phenotype of breast cancer. Histopathology 2005;47:458-466.

65 Matos I, Dufloth R, Alvarenga $\mathrm{M}$, et al. p63, cytokeratin 5, and P-cadherin: three molecular markers to distinguish basal phenotype in breast carcinomas. Virchows Arch 2005;447:688-694.

66 Paredes J, Lopes N, Milanezi F, et al. P-cadherin and cytokeratin 5: useful adjunct markers to distinguish basal-like ductal carcinomas in situ. Virchows Arch 2007;450:73-80.

67 van de Rijn M, Perou CM, Tibshirani R, et al. Expression of cytokeratins 17 and 5 identifies a group of breast carcinomas with poor clinical outcome. Am J Pathol 2002;161:1991-1996.

68 Hicks DG, Short SM, Prescott NL, et al. Breast cancers with brain metastases are more likely to be estrogen receptor negative, express the basal cytokeratin CK5/ 6, and overexpress HER2 or EGFR. Am J Surg Pathol 2006;30:1097-1104.

69 Liu ZB, Wu J, Ping B, et al. Basal cytokeratin expression in relation to immunohistochemical and clinical characterization in breast cancer patients with triple-negative phenotype. Tumori 2009;95: $53-62$.

70 Sousa B, Paredes J, Milanezi F, et al. P-cadherin, vimentin and CK14 for identification of basal-like phenotype in breast carcinomas: an immunohistochemical study. Histol Histopathol 2010;25:963-974.

71 Shao MM, Zhang F, Meng G, et al. Epidermal growth factor receptor gene amplification and protein overexpression in basal-like carcinoma of the breast. Histopathology 2011;59:264-273.

72 Martin V, Botta F, Zanellato E, et al. Molecular characterization of EGFR and EGFR-downstream pathways in triple negative breast carcinomas with basal like features. Histol Histopathol 2012;27: 785-792.

73 Cheang MCU, Treaba DO, Speers CH, et al. Immunohistochemical detection using the new rabbit monoclonal antibody SP1 of estrogen receptor in breast cancer is superior to mouse monoclonal antibody 1D5 in predicting survival. J Clin Oncol 2006;24: 5637-5644.

74 Collett K, Eide GE, Arnes J, et al. Expression of enhancer of zeste homologue 2 is significantly associated with increased tumor cell proliferation and is a marker of aggressive breast cancer. Clin Cancer Res 2006;12:1168-1174.

75 Kleer CG, Cao Q, Varambally S, et al. EZH2 is a marker of aggressive breast cancer and promotes neoplastic transformation of breast epithelial cells. Proc Natl Acad Sci USA 2003;100:11606-11611.
76 De Brot M, Rocha RM, Soares FA, et al. Prognostic impact of the cancer stem cell related markers ALDH1 and EZH2 in triple negative and basal-like breast cancers. Pathology 2012;44:303-312.

77 Holm K, Grabau D, Lövgren K, et al. Global H3K27 trimethylation and EZH2 abundance in breast tumor subtypes. Mol Oncol 2012;6:494-506.

78 Hussein YR, Sood AK, Bandyopadhyay S, et al. Clinical and biological relevance of enhancer of zeste homolog 2 in triple-negative breast cancer. Hum Pathol 2012;43:1638-1644.

79 Zhang H, Rakha E, Ball G, et al. The proteins FABP7 and OATP2 are associated with the basal phenotype and patient outcome in human breast cancer. Breast Cancer Res Treat 2009;121:41-51.

80 Tang XY, Umemura S, Tsukamoto $\mathrm{H}$, et al. Overexpression of fatty acid binding protein-7 correlates with basal-like subtype of breast cancer. Pathol Res Pract 2010;206:98-101.

81 Alshareeda AT, Rakha EA, Nolan CC, et al. Fatty acid binding protein 7 expression and its sub-cellular localization in breast cancer. Breast Cancer Res Treat 2012;134:519-529.

82 Yoder BJ, Tso E, Skacel M, et al. The expression of fascin, an actin-bundling motility protein, correlates with hormone receptor-negative breast cancer and a more aggressive clinical course. Clin Cancer Res 2005;11:186-192.

83 Rodriguez-Pinilla SM, Sarrio D, Honrado E, et al. Prognostic significance of basal-like phenotype and fascin expression in node-negative invasive breast carcinomas. Clin Cancer Res 2006;12:1533-1539.

84 Sarrió D, Rodriguez-Pinilla SM, Hardisson D, et al. Epithelial-mesenchymal transition in breast cancer relates to the basal-like phenotype. Cancer Res 2008;68:989-997.

85 Wang J, Ray P, Sim M, et al. FOXC1 regulates the functions of human basal-like breast cancer cells by activating NF-кB signaling. Oncogene 2012;31: 4798-4802.

86 Ray PS, Bagaria SP, Wang J, et al. Basal-like breast cancer defined by FOXC1 expression offers superior prognostic value: a retrospective immunohistochemical study. Ann Surg Oncol 2011;18:3839-3847.

87 Ricardo SAV, Milanezi F, Carvalho ST, et al. HER2 evaluation using the novel rabbit monoclonal antibody SP3 and CISH in tissue microarrays of invasive breast carcinomas. J Clin Pathol 2007;60: 1001-1005.

88 Walter O, Prasad M, Lu S, et al. IMP3 is a novel biomarker for triple negative invasive mammary carcinoma associated with a more aggressive phenotype. Human Pathol 2009;40:1528-1533.

89 Sidoni A, Cartaginese F. IMP3 expression in triplenegative breast carcinoma. Hum Pathol 2010;41: 1355-1356.

90 Vranic S, Gurjeva O, Frkovic-Grazio S, et al. A proposed novel basal phenotype marker, is commonly overexpressed in adenoid cystic carcinomas but not in apocrine carcinomas of the breast. App Immunohisto Mol Morph 2011;19:413-416.

91 Samanta S, Sharma V, Khan A, et al. Regulation of IMP3 by EGFR signaling and repression by ER $\beta$ : implications for triple-negative breast cancer. Oncogene 2012;31:4689-4697.

92 Fedele CG, Ooms LM, Ho M, et al. Inositol polyphosphate 4-phosphatase II regulates PI3K/akt signaling 
and is lost in human basal-like breast cancers. Proc Natl Acad Sci USA 2010;107:22231-22236.

93 Gewinner C, Wang ZC, Richardson A, et al. Evidence that inositol polyphosphate 4-phosphatase type II is a tumor suppressor that inhibits PI3K signaling. Cancer Cell 2009;16:115-125.

94 Weigman VJ, Chao HH, Shabalin AA, et al. Basal-like breast cancer DNA copy number losses identify genes involved in genomic instability, response to therapy, and patient survival. Breast Cancer Res Treat 2012;133:865-880.

$95 \mathrm{Lu} \mathrm{S}$, Simin K, Khan A, et al. Analysis of integrin Beta4 expression in human breast cancer: association with basal-like tumors and prognostic significance. Clin Cancer Res 2008;14:1050-1058.

96 Rodriguez-Pinilla SM, Sarrio D, Honrado E, et al. Vimentin and laminin expression is associated with basal-like phenotype in both sporadic and BRCA1-associated breast carcinomas. J Clin Pathol 2007;60:1006-1012.

97 Carpenter PM, Wang-Rodriguez J, Chan OTM, et al. Laminin 5 expression in metaplastic breast carcinomas. Am J Surg Pathol 2008;32:345-353.

98 Kwon SY, Chae SW, Wilczynski SP, et al. Laminin 332 expression in breast carcinoma. App Immunohisto Mol Morph 2012;20:159-164.

99 Garcia S, Dalès J, Charafe-Jauffret E, et al. Poor prognosis in breast carcinomas correlates with increased expression of targetable CD146 and c-met and with proteomic basal-like phenotype. Human Pathol 2007;38:830-841.

100 Gastaldi S, Comoglio PM, Trusolino L. The met oncogene and basal-like breast cancer: another culprit to watch out for. Breast Cancer Res 2010;12:208.

101 Ponzo MG, Park M. The met receptor tyrosine kinase and basal breast cancer. Cell Cycle 2010;9:1043-1050.

102 Charafe-Jauffret E, Monville F, Bertucci F, et al. Moesin expression is a marker of basal breast carcinomas. Int J Cancer 2007;121:1779-1785.

103 Wang CC, Liau JY, Lu YS, et al. Differential expression of moesin in breast cancers and its implication in epithelial-mesenchymal transition. Histopathology 2012;61:78-87.

104 Krüger K, Stefansson I, Collett K, et al. Microvessel proliferation by co-expression of endothelial nestin and ki-67 is associated with a basal-like phenotype and aggressive features in breast cancer. Breast 2013;22:282-288.

105 Li H, Cherukuri P, Li N, et al. Nestin is expressed in the basal/myoepithelial layer of the mammary gland and is a selective marker of basal epithelial breast tumors. Cancer Res 2007;67:501-510.

106 Parry S, Savage K, Marchio C, et al. Nestin is expressed in basal-like and triple negative breast cancers. J Clin Pathol 2008;61:1045-1050.

107 Piras F, Ionta M, Lai S, et al. Nestin expression associates with poor prognosis and triple negative phenotype in locally advanced (T4) breast cancer. Eur J Histochem 2011;55:e39-e45.

108 Liu C, Chen B, Zhu J, et al. Clinical implications for nestin protein expression in breast cancer. Cancer Sci 2009;101:815-819.

109 Reis-Filho JS, Steele D, Di Palma S, et al. Distribution and significance of nerve growth factor receptor (NGFR/p75NTR) in normal, benign and malignant breast tissue. Mod Pathol 2006;19:307-319.
110 Popnikolov NK, Cavone SM, Schultz PM, et al. Diagnostic utility of p75 neurotrophin receptor (p75NTR) as a marker of breast myoepithelial cells. Mod Pathol 2005;18:1535-1541.

111 Herschkowitz J, He X, Fan C, et al. The functional loss of the retinoblastoma tumour suppressor is a common event in basal-like and luminal B breast carcinomas. Breast Cancer Res 2008;10:R75.

112 Subhawong AP, Subhawong T, Nassar H, et al. Most basal-like breast carcinomas demonstrate the same $\mathrm{rb}-/ \mathrm{p} 16+$ immunophenotype as the HPV-related poorly differentiated squamous cell carcinomas which they resemble morphologically. Am J Surg Pathol 2009;33:163-175.

113 Bohn OL, Fuertes-Camilo M, Navarro L, et al. p16INK4a expression in basal-like breast carcinoma. Int J Clin Exp Pathol 2010;3:600-607.

114 Traub F, Mengel M, Lück H, et al. Prognostic impact of Skp2 and p27 in human breast cancer. Breast Cancer Res Treat 2006;99:185-191.

115 Alsner J, Jensen V, Kyndi M, et al. A comparison between p53 accumulation determined by immunohistochemistry and TP53 mutations as prognostic variables in tumours from breast cancer patients. Acta Oncol 2008;47:600-607.

116 Manié E, Vincent-Salomon A, Lehmann-Che J, et al. High frequency of TP53 mutation in BRCA1 and sporadic basal-like carcinomas but not in BRCA1 luminal breast tumors. Cancer Res 2009;69:663-671.

117 Chae BJ, Bae JS, Lee A, et al. p53 as a specific prognostic factor in triple-negative breast cancer. Jpn J Clin Oncol 2009;39:217-224.

118 Matkovic B, Juretic A, Separovic V, et al. Immunohistochemical analysis of ER, PR, HER-2, CK 5/6, p63 and EGFR antigen expression in medullary breast cancer. Tumori 2008;94:838-844.

119 Arnes JB, Brunet J, Stefansson I, et al. Placental cadherin and the basal epithelial phenotype of BRCA1-related breast cancer. Clin Cancer Res 2005; 11:4003-4011.

120 Potemski P, Kusinska R, Kubiak R, et al. Relationship of P-cadherin expression to basal phenotype of breast carcinoma. Polish J Pathol 2007;58:183-188.

121 Turashvili G, McKinney SE, Goktepe O, et al. P-cadherin expression as a prognostic biomarker in a 3992 case tissue microarray series of breast cancer. Mod Pathol 2010;24:64-81.

122 Liu N, Yu Q, Liu T, et al. P-cadherin expression and basal-like subtype in breast cancers. Med Oncol 2012;29:2606-2612.

123 Kuroda H, Ishida F, Nakai M, et al. Basal cytokeratin expression in relation to biological factors in breast cancer. Human Pathol 2008;39:1744-1750.

124 Baak J, Gudlaugsson E, Skaland I, et al. Proliferation is the strongest prognosticator in node-negative breast cancer: significance, error sources, alternatives and comparison with molecular prognostic markers. Breast Cancer Res Treat 2009;115:241-254.

125 Skaland I, Janssen EAM, Gudlaugsson E, et al. The prognostic value of the proliferation marker phosphohistone H3 (PPH3) in luminal, basal-like and triple negative phenotype invasive lymph nodenegative breast cancer. Cell Oncol 2009;31:261-271.

126 Bossard C, Jarry A, Colombeix C, et al. Phosphohistone H3 labelling for histoprognostic grading of breast adenocarcinomas and computer-assisted determination of mitotic index. J Clin Pathol 2006;59:706-710. 
127 Skaland I, Janssen EAM, Gudlaugsson E, et al. Phosphohistone H3 expression has much stronger prognostic value than classical prognosticators in invasive lymph node-negative breast cancer patients less than 55 years of age. Mod Pathol 2007;20: 1307-1315.

128 Rocha R, Nunes C, Rocha G, et al. Rabbit monoclonal antibodies show higher sensitivity than mouse monoclonals for estrogen and progesterone receptor evaluation in breast cancer by immunohistochemistry. Pathol Res Prac 2008;204:655-662.

129 Arai K, Takano S, Teratani T, et al. S100A8 and S100A9 overexpression is associated with poor pathological parameters in invasive ductal carcinoma of the breast. Curr Cancer Drug Targets 2008;8: 243-252.

130 Cross SS, Hamdy FC, Deloulme JC, et al. Expression of S100 proteins in normal human tissues and common cancers using tissue microarrays: S100A6, S100A8, S100A9 and S100A11 are all overexpressed in common cancers. Histopathology 2005;46: 256-269.

131 Gonçalves A, Charafe-Jauffret E, Bertucci F, et al. Protein profiling of human breast tumor cells identifies novel biomarkers associated with molecular subtypes. Mol Cell Proteomics 2008;7: 1420-1433.

132 Signoretti S, Di Marcotullio L, Richardson A, et al. Oncogenic role of the ubiquitin ligase subunit Skp2 in human breast cancer. J Clin Invest 2002;110: 633-641.

133 Hao L, Zhang C, Qiu Y, et al. Recombination of CXCR4, VEGF, and MMP-9 predicting lymph node metastasis in human breast cancer. Cancer Letters 2007;253:34-42.

134 Liu Y, Tamimi RM, Collins LC, et al. The association between vascular endothelial growth factor expression in invasive breast cancer and survival varies with intrinsic subtypes and use of adjuvant systemic therapy: Results from the nurses' health study. Breast Cancer Res Treat 2011;129:175-184.

135 Linderholm BK, Hellborg H, Johansson U, et al. Significantly higher levels of vascular endothelial growth factor (VEGF) and shorter survival times for patients with primary operable triple-negative breast cancer. Ann Oncol 2009;20:1639-1646.

136 Kusinska R, Kordek R, Pluciennik E, et al. Does vimentin help to delineate the so-called 'basal type breast cancer'? J Exp Clin Cancer Res 2009;28: 118-126.

137 Chen MH, Wai-Cheong Yip G, Tse GM, et al. Expression of basal keratins and vimentin in breast cancers of young women correlates with adverse pathologic parameters. Mod Pathol 2008;21:1183-1191.

138 Holm S. A simple sequentially rejective multiple test procedure. Scand J Statist 1979;6:65-70.

139 Yerushalmi R, Woods R, Ravdin PM, et al. Ki67 in breast cancer: Prognostic and predictive potential. Lancet Oncol 2010;11:174-183.

140 Sheri A, Dowsett M. Developments in Ki67 and other biomarkers for treatment decision making in breast cancer. Ann Oncol 2012;23:x219-x227.

141 Williams DJ, Cohen C, Darrow M, et al. Proliferation (ki-67 and phosphohistone H3) and oncotype DX recurrence score in estrogen receptor-positive breast cancer. App Immunohisto Mol Morph 2011;19: 431-436.
142 Chia SK, Bramwell VH, Tu D, et al. A 50-gene intrinsic subtype classifier for prognosis and prediction of benefit from adjuvant tamoxifen. Clin Cancer Res 2012;18:4465-4472.

143 Cheang MC, Voduc KD, Tu D, et al. Responsiveness of intrinsic subtypes to adjuvant anthracycline substitution in the NCIC.CTG MA.5 randomized trial. Clin Cancer Res 2012;18:2402-2412.

144 Crown J, O’Shaughnessy J, Gullo G. Emerging targeted therapies in triple-negative breast cancer. Ann Oncol 2012;23(Suppl 6):vi56-vi65.

145 Miller TW, Rexer BN, Garrett JT, et al. Mutations in the phosphatidylinositol 3-kinase pathway: role in tumor progression and therapeutic implications in breast cancer. Breast Cancer Res 2011;13:224-236.

146 Adamo B, Deal AM, Burrows E, et al. Phosphatidylinositol-3-kinase pathway activation in breast cancer brain metastases. Breast Cancer Res 2011;13: R125-R136.

147 Hakim S, Bertucci M, Conduit S, et al. Inositol polyphosphate phosphatases in human disease. Curr Top Microbiol Immunol 2012;362:247-314.

148 Balakrishnan A, Chaillet JR. Role of the inositol polyphosphate-4-phosphatase type II Inpp4b in the generation of ovarian teratomas. Dev Biol 2013;373:118-129.

149 Naylor TL, Greshock J, Wang Y, et al. High resolution genomic analysis of sporadic breast cancer using array-based comparative genomic hybridization. Breast Cancer Res 2005;7:R1186-R1198.

150 Bergamaschi A, Kim YH, Wang P, et al. Distinct patterns of DNA copy number alteration are associated with different clinicopathological features and gene-expression subtypes of breast cancer. Genes Chromosomes Cancer 2006;45:1033-1040.

151 Cancer Genome Atlas Network. Comprehensive molecular portraits of human breast tumours. Nature 2012;490:61-70.

152 Dahlstrand J, Collins VP, Lendahl U. Expression of the class VI intermediate filament nestin in human central nervous system tumors. Cancer Res 1992;52:5334-5341.

153 Ehrmann J, Kolár Z, Mokrý J. Nestin as a diagnostic and prognostic marker: immunohistochemical analysis of its expression in different tumours. J Clin Pathol 2005;58:222-223.

154 Kolar Z, Ehrmann J, Turashvili G, et al. A novel myoepithelial/progenitor cell marker in the breast? Virchows Archiv 2007;450:607-609.

155 Rakha EA, Elsheikh SE, Aleskandarany MA, et al. Triple-negative breast cancer: distinguishing between basal and nonbasal subtypes. Clin Cancer Res 2009;15:2302-2310.

156 Yuan Z, Ghosh D. Combining multiple biomarker models in logistic regression. Biometrics 2008;64: 431-439.

157 Bansal A, Pepe MS. When does combining markers improve classification performance and what are implications for practice? Stat Med 2013;32: 1877-1892.

158 Sotiriou C, Pusztai L. Gene-expression signatures in breast cancer. N Engl J Med 2009;360:790-800.

159 Mehta RJ, Jain RK, Leung S, et al. FOXA1 is an independent prognostic marker for ER-positive breast cancer. Breast Cancer Res Treat 2012;131: 881-890. 
160 Pepe MS, Janes H, Longton G, et al. Limitations of the odds ratio in gauging the performance of a diagnostic, prognostic, or screening marker. Am J Epidemiol 2004;159:882-890.

161 Harrison J, Kulkarni K, Baguneid M, et al. Oxford Handbook of Key Clinical Evidence. Oxford University Press: New York, NY, USA, 2009.

162 Rakha E, Reis-Filho J, Ellis I. Combinatorial biomarker expression in breast cancer. Breast Cancer Res Treat 2010;120:293-308.

163 Pepe MS, Feng Z, Janes H, et al. Pivotal evaluation of the accuracy of a biomarker used for classification or prediction: standards for study design. J Natl Cancer Inst 2008;100:1432-1438. 